\title{
Thyroid autoimmunity and obstetric outcomes in women with recurrent miscarriage: a case-control study
}

\author{
Kusum Lata', Pinaki Dutta², Subbiah Sridhar ${ }^{2}$, Minakshi Rohilla', \\ Anand Srinivasan ${ }^{3}$, G R V Prashad', Viral N Shah² and Anil Bhansali²
}

Departments of ${ }^{1}$ Obstetrics and Gynecology ${ }^{2}$ Endocrinology ${ }^{3}$ Pharmacology, Post Graduate Institute of Medical Education and Research (PGIMER), Chandigarh, India

Correspondence should be addressed to A Bhansali Email

anilbhansaliendocrine@ rediffmail.com

\begin{abstract}
Objectives: Thyroid antibody positivity during pregnancy has been associated with adverse outcomes including miscarriage and preterm delivery. The aim of the study is to evaluate the obstetric outcome in pregnant women with recurrent miscarriage and their response to levothyroxine (L-T 4$)$ therapy.

Study design and methods: All pregnant and non-pregnant women between 21 and 35 years of age with a history of two or more consecutive miscarriages were included in the study. A third group comprising 100 pregnant women without a history of miscarriage were taken as healthy controls. Thyroid autoimmunity, prevalence of subclinical hypothyroidism and maternal and foetal complications were analysed in all the groups with appropriate statistical methods.

Results: The mean age of the patients included in the study was $27.0 \pm 3.1$ years. Of 100 pregnant patients with previous recurrent miscarriage, thyroid autoimmunity (thyroid peroxidase antibody $\left(\mathrm{TPOAb}^{+}\right)>34 \mathrm{U} / \mathrm{ml}$ ) was found in $31 \%$ of the cases. The incidence of subclinical hypothyroidism was higher in TPOAb ${ }^{+}$group than in TPOAb ${ }^{-}$group (52 vs 16\%; $P=0.0002$ ). There was no difference in the prevalence of miscarriage or obstetric outcomes between recurrent miscarriage and healthy pregnant women group irrespective of TPO status. Conclusions: The prevalence of thyroid autoimmunity was higher in pregnant women with a history of recurrent abortion compared with healthy pregnant control population. Following $\mathrm{L}^{-} \mathrm{T}_{4}$ treatment, there was no difference in prevalence of miscarriage between hypothyroid and euthyroid individuals in TPOAb ${ }^{+}$women.
\end{abstract}

\section{Key Words}

- recurrent miscarriage

- thyroid peroxidase

- hypothyroidism

- preterm birth

\section{Introduction}

Miscarriage is the spontaneous loss of the conceptus before 20 weeks of gestation. Potential amount of possible miscarriage before pregnancy is recognised to be about
$30 \%$. In clinically recognised pregnancy, it is $10-15 \%$ before 8 th week and $3 \%$ between 8 th and 28 th weeks. Recurrent miscarriage, defined as loss of two or more consecutive http://www.endocrineconnections.org DOI: 10.1530/EC-13-0012 (c) 2013 The authors Published by Bioscientifica Ltd

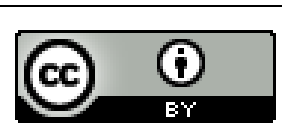

This work is licensed under a Creative Commons Attribution 3.0 Unported License. 
pregnancies (ASRM Practice committee Report, 2008), occurs in $\sim 1-2 \%$ of couples attempting to bear children $(1,2,3,4)$.

Several disorders are known to contribute to recurrent miscarriage including: chromosomal anomalies; anticardiolipin antibodies; endocrine disorders such as poorly controlled diabetes mellitus; hyperprolactinaemia and thyroid diseases; and pelvic anatomic abnormalities (5). Recurrent miscarriage can be classified as either primary or secondary. Primary aborters are women who have lost all their pregnancies, whereas secondary aborters have had at least one live born infant.

Autoimmune thyroid disease (AITD) is by far the most frequent cause of hypothyroidism in women of reproductive age. The prevalence of hypothyroidism in the general population of reproductive age is $\sim 2-3 \%(6,7)$. Overt hypothyroidism is commonly associated with infertility, as thyroid hormones have a direct effect on granulosa cells, luteal cells and oocyte maturation (8). Euthyroid women with thyroid autoimmunity are twice as likely to experience spontaneous miscarriages (9). This probably represents a generalised activation of the immune system, or an increased risk of progression to subclinical hypothyroidism, or it could be due to the transplacental transfer of thyroid receptor blocking antibodies $(10,11)$. Hence, there is a need to screen for subclinical hypothyroidism and thyroid autoimmunity in pregnancy, especially in women with a history of miscarriages.

However, the management of women with recurrent miscarriage who have thyroid autoimmunity remains controversial. Some investigators recommend the use of empirical thyroxine $\left(\mathrm{T}_{4}\right)$ therapy in women with thyroid peroxidase antibody positive $\left(\mathrm{TPOAb}^{+}\right.$) autoimmunity, although there was no evidence of hypothyroidism (12). A few studies showed that empirical $\mathrm{T}_{4}$ therapy in patients with $\mathrm{TPOAb}^{+}$did not improve the obstetrical outcome (13). This study will evaluate the obstetric outcome in pregnant women with recurrent miscarriage and response to levothyroxine (L-T 4 ) therapy.

\section{Research design and methods}

One hundred pregnant and 25 non-pregnant women between 21 and 35 years of age with a history of two or more consecutive miscarriages were included in the study. A third group comprising 100 pregnant women without a history of miscarriage were taken as healthy controls. Among the 100 pregnant women with recurrent miscarriages, $85 \%$ were recruited in the first trimester and the remaining (15\%) in the second trimester. Sixty-seven per cent of patients had primary recurrent abortion while the rest had secondary recurrent abortion. This casecontrol study was conducted between June 2010 and December 2011 in the Department of Obstetrics and Gynaecology, and the Department of Endocrinology, Postgraduate Institute of Medical Education and Research, Chandigarh, India. It was a prospective study for pregnant women with recurrent abortions and cross sectional for non-pregnant women with a history of recurrent abortions. The study was approved by the Institute's Ethics Committee. All patients provided written informed consent for participation in the trial.

\section{Eligibility criteria}

All pregnant and non-pregnant women with a history of two or more consecutive miscarriages in the age group of 21-35 years were included in the study. Women with known autoimmune disorders, already on treatment for thyroid dysfunction, and a history of cervical incompetence or any other uterine pathology were excluded. All patients underwent a comprehensive medical evaluation including a detailed history and a thorough physical examination.

\section{Hormonal profile}

A $3 \mathrm{ml}$ volume of venous blood was collected in EDTA vacutainers at the initial visit. Each blood sample was analysed for $\mathrm{TSH}$, free tri-iodothyronine $\left(\mathrm{FT}_{3}\right)$, free $\mathrm{T}_{4}\left(\mathrm{FT}_{4}\right)$ and anti-TPO by electro-chemiluminescence immunoassay (ELECSYS-2010, Roche-Hitachi Diagnostics). The reference range for the above hormones are as follows: TSH, RR: $0.27-4.2 \mu \mathrm{lU} / \mathrm{ml}$ (inter-assay coefficient of variation $(\mathrm{CV})$ 2.5-3.2\%, intra-assay CV 0.5-1.5\%); $\mathrm{FT}_{3}, \mathrm{RR}: 1.7-4.2 \mathrm{ng} / \mathrm{ml}$ (inter-assay CV 1.4-3.2\%, intra-assay CV 0.5-2.0\%); $\mathrm{FT}_{4}$, RR: $0.7-1.8 \mathrm{ng} / \mathrm{ml}$ (inter-assay CV $1.0-2.5 \%$, intra-assay $\mathrm{CV}$ 1.0-2.5\%); and anti-TPO, RR: $<34 \mathrm{IU} / \mathrm{ml}$.

All patients with $\mathrm{TPOAb}^{+}$were treated with $25 \mu \mathrm{g} \mathrm{L}_{\mathrm{L}} \mathrm{T}_{4}$ and titrated according to TSH at the time of recruitment into the study. The patients who had subclinical hypothyroidism were treated as deemed necessary. All patients were followed in the antenatal outpatient department every 4 weeks until 28 weeks. Ultrasonography (USG) was done at 8 weeks in all pregnant women for confirmation of viability and a repeat scan was done around 18 weeks of gestation to find any foetal anomalies. After 28 weeks, they were followed fortnightly until 37 weeks. All patients were monitored for development of any sign or symptom of pre-eclampsia, intrauterine

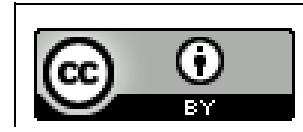

This work is licensed under a Creative Commons Attribution 3.0 Unported License. 
growth retardation (IUGR) or preterm labour. USG for foetal growth and biophysical profile was done as per clinical findings. After 37 weeks, subjects were followed weekly and were delivered according to the obstetric indications. Details of the mode of delivery and any intrapartum or post partum complications were noted. After delivery, the birth weight, gestational age and APGAR score at 1 and $5 \mathrm{~min}$, and the presence of any congenital malformations were noted.

Maternal complications were noted as spontaneous abortion, hypertensive complications (gestational hypertension, pre-eclampsia and eclampsia), gestational diabetes mellitus, intrahepatic cholestasis of pregnancy, preterm labour, IUGR, postdatism, preterm premature rupture of membranes and post partum haemorrhage. Neonatal outcomes were measured in the form of prematurity (delivery between 20 and 37 weeks), APGAR score, birth weight and congenital malformation.

Twenty-five age-matched non-pregnant women with a history of recurrent abortions were also recruited and investigated for causes of recurrent abortions. Blood samples for thyroid function tests were taken at first visit and treated according to the results. A third group comprising 100 pregnant women without any history of miscarriage were taken as healthy controls. Table 1 compares the baseline characteristics, thyroid hormone profile and maternal-foetal outcome between the pregnant patients of the miscarriage group and the healthy group.

\section{Statistical analysis}

The data have been presented as mean \pm s.D. if it has a normal distribution; otherwise, median with interquartile range was used. The normality was assessed by Kolmogorov-Smirnov and Anderson-Darling test. Unpaired $t$-test was used for normal data and Mann-Whitney $U$ test was used for non-normal data. To analyse the dichotomous data, odds ratio or Fisher's exact test was used. Multivariate analysis was carried out to determine the effect of $\mathrm{T}_{3}, \mathrm{~T}_{4}$, TSH and anti-TPO on percentage of live birth per individual. The covariates included for multivariate analysis were age, weight, $\mathrm{T}_{3}$, $\mathrm{T}_{4}, \mathrm{TSH}$, anti-TPO titre, period of gestation and haemoglobin level of the patients. A $P$ value of $<0.05$ was considered significant. All the data were analysed with Minitab 16.00 and SPSS 11.

Table 1 Comparison of pregnant women with recurrent miscarriage and healthy pregnant control without any miscarriage. Data are expressed as mean \pm s.D.

\begin{tabular}{|c|c|c|c|}
\hline Parameters & $\begin{array}{l}\text { Pregnant women with } \\
\text { recurrent miscarriage } \\
\qquad(n=100)\end{array}$ & $\begin{array}{l}\text { Healthy pregnant control } \\
\text { without miscarriage } \\
\qquad(n=100)\end{array}$ & $P$ value \\
\hline Age (years) & $28.0 \pm 3.4$ & $27.0 \pm 3.1$ & 0.04 \\
\hline Gravida $^{a}$ (range) & $4(3-5)$ & $2(2-2)$ & $<0.001$ \\
\hline $\mathrm{FT}_{3}{ }^{\mathrm{a}}$ (ng/ml (range)) & $2.5(2.1-3.1)$ & $2.7(2-3.1)$ & 0.76 \\
\hline $\mathrm{FT}_{4}{ }^{\mathrm{a}}$ (ng/ml (range)) & $1.2(1.0-1.4)$ & $1.1(1.0-1.3)$ & 0.82 \\
\hline $\mathrm{TSH}^{\mathrm{a}}(\mu \mathrm{IU} / \mathrm{ml}$ (range)) & $2.0(1.6-2.5)$ & $2.0(1.4-2.5)$ & 0.58 \\
\hline TPOAb positivity (\%) & 31 & 18 & 0.031 \\
\hline Period of gestation (weeks) & 38.4 & 38.0 & 0.23 \\
\hline Normal vaginal delivery & 75 & 72 & 0.63 \\
\hline Operative vaginal delivery & 4 & 4 & 0.99 \\
\hline Lower segment caesarean section (LSCS) & 17 & 22 & 0.37 \\
\hline Gestational hypertension & 6 & 4 & 0.75 \\
\hline Preterm labour & 12 & 16 & 0.41 \\
\hline IUGR & 6 & 4 & 0.75 \\
\hline Intrahepatic cholestasis of pregnancy & 5 & 4 & 0.99 \\
\hline Premature rupture of membrane & 1 & 3 & 0.62 \\
\hline Birth weight (kg) & 2.8 & 2.8 & 0.33 \\
\hline \multicolumn{4}{|l|}{ a Median. } \\
\hline $\begin{array}{l}\text { http://www.endocrineconnections.org } \\
\text { DOI: } 10.1530 / \text { EC-13-0012 }\end{array}$ & $\begin{array}{l}3 \text { The authors } \\
\text { scientifica Ltd }\end{array}$ & $\begin{array}{l}\text { This work is licensed } \\
\text { Attribution } 3.0 \text { Unp }\end{array}$ & $\begin{array}{l}\text { eative Commons } \\
\text { e. }\end{array}$ \\
\hline
\end{tabular}




\section{Results}

The mean age of the women included in the study was $27.0 \pm 3.1$ years. The odds ratio of having $\mathrm{TPOAb}^{+}$was higher (2.05) in the miscarriage group compared with the healthy group.

Of 100 pregnant patients with previous recurrent miscarriage, thyroid autoimmunity (anti-TPO >34 U/ml) was found in $31 \%(P=0.031)$ and subclinical hypothyroidism was observed in $27 \%(P=0.74)$ of the cases. The incidence of subclinical hypothyroidism was higher in the $\mathrm{TPOAb}^{+}$group than in the TPOAb ${ }^{-}$group (52 vs 16\%; $P=0.0002)$. TPOAb titre was significantly higher in the hypothyroid group than in the euthyroid with recurrent pregnancy loss group $(81.7 \pm 132.7$ vs $31.9 \pm 68.7 \mathrm{IU} / \mathrm{ml}$, $P=0.016)$. In the healthy control group, comprised of pregnant women without a history of abortion, the prevalence of subclinical hypothyroidism was $24 \%$ and TPO positivity was $18 \%(P=0.70)$.

There was no difference in the prevalence of miscarriage between hypothyroid and euthyroid individuals in anti-TPO-positive women $(P=0.23)$. On linear regression in euthyroid (after exclusion for hypothyroidism) women with anti-TPO positivity, the percentage of live birth was found to correlate with level of TPO antibody $(R=0.17, P=0.01)$. Similarly, on multivariate linear regression, the percentage of live birth was found to correlate with the level of $\mathrm{FT}_{4}(R=0.17, P=0.001)$. Comparison of $\mathrm{TPOAb}^{+}$and $\mathrm{TPOAb}^{-}$pregnant women with recurrent miscarriage is shown in Table 2 . The modes of delivery between the two groups were comparable $(P=0.7)$. Among the four aborters in the recurrent miscarriage group, two were in the $\mathrm{TPOAb}^{+}$group and the remaining were in the $\mathrm{TPOAb}^{-}$group with no statistically significant difference $(P=0.39)$. Intrahepatic cholestasis was more common in the $\mathrm{TPOAb}^{-}$group $(P=0.03)$. The odds ratio of having miscarriage was increased (5.62) when $\mathrm{TPOAb}^{+}$with elevated TSH was compared with normal values.

Twenty-five non-pregnant women with recurrent miscarriage were also analysed for their pregnancy outcome. The mean TSH was $2.7 \pm 1.6 \mu \mathrm{IU} / \mathrm{ml}$ and the mean TPO was $28.0 \pm 16.8 \mathrm{IU} / \mathrm{ml}$. The prevalence of thyroid autoimmunity and subclinical hypothyroidism in this group was $20 \%$ each.

\section{Discussion}

In this study, the prevalence of thyroid autoimmunity was higher in pregnant women with a history of recurrent

http://www.endocrineconnections.org
$\begin{array}{lr}\text { DOI: } 10.1530 / \text { EC-13-0012 } 2013 \text { The authors } \\ \text { Published by Bioscientifica Ltd }\end{array}$

abortion compared with the healthy pregnant control population. Even though the TSH value was higher in the $\mathrm{TPOAb}^{+}$group than in the TPOAb ${ }^{-}$group, the prevalence of subclinical hypothyroidism was comparable between the two groups. There was no absolute difference in the prevalence of miscarriage between subclinical hypothyroid and euthyroid pregnant women irrespective of TPO status. However, the odds of having miscarriage in the $\mathrm{TPOAb}^{+}$group increases with rising TSH level compared with normal TSH level. A similar phenomenon was observed with decreasing $\mathrm{FT}_{4}$ levels. There was no difference in any of the parameters between pregnant women with recurrent miscarriages compared with nonpregnant women with a history of recurrent abortion.

The prevalence of thyroid autoimmunity in our study was $24 \%$ (31\% in pregnant women with recurrent abortion) while it was significantly lower (18\%) in the healthy group (31 vs $18 \%, P=0.03$ ). The prevalence in the general population described in the literature is $10-15 \%(14,15)$. The odds ratio of having $\mathrm{TPOAb}^{+}$was higher (2.05) in the miscarriage group, indicated a strong association between them. A meta-analysis by Prummel et al. (16) showed that $\mathrm{TPOAb}^{+}$was associated with a twofold increased risk of miscarriage as shown in this study. In both the groups, the outcome of current pregnancy was not influenced by TPO positivity or by TSH values. This could be becuase all cases of either isolated TPOAb positivity or of elevated TSH were treated during the course of pregnancy.

Similar results were found by Negro et al. (12), who found the miscarriage rate in the $\mathrm{TPOAb}^{+}$group supplemented with $\mathrm{T}_{4}$ was comparable to healthy controls (3.5 vs $2.4 \%$ ). However, unlike our study population, these patients had no history of recurrent miscarriage. None of our patients had isolated hypothyroxinaemia. However, the odds of having the miscarriage were increased with decreasing $\mathrm{FT}_{4}$ values. As expected, the mean TSH in the $\mathrm{TPOAb}^{+}$group was higher $(3.1 \pm 1.9)$ compared with those in the $\mathrm{TPOAb}^{-}$group $(2.0 \pm 1.0, P<0.001)$. A possible explanation for high TSH in the $\mathrm{TPOAb}^{+}$group is a reduced functional thyroid reserve associated with chronic autoimmune thyroiditis $(17,18)$.

In this study, the prevalence of subclinical hypothyroidism was $24 \%$ in healthy pregnant women without miscarriage, and $27 \%$ in pregnant women with a history of recurrent miscarriage $(P=0.74)$. This is higher than the reported prevalence of $10-16 \%$ in the literature $(14,15)$. Such a high prevalence could be due to selection bias, lack of iodine status in our patients, different assay methods and different cutoff levels of TSH used to define subclinical hypothyroid in previous studies.

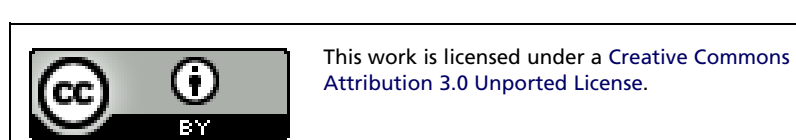


Table 2 Comparison of TPOAb ${ }^{+}$and TPOAb ${ }^{-}$pregnant women with recurrent miscarriage. Data are expressed as mean \pm s.D. *indicates statistical significance $(P<0.05)$.

\begin{tabular}{|c|c|c|c|}
\hline Parameter & TPOAb $^{+}$group $(n=31)$ & TPOAb $^{-}$group $(n=69)$ & $P$ value \\
\hline Age (years) & $26.4 \pm 3.0$ & $27.3 \pm 3.1$ & 0.1 \\
\hline Free $T_{3}(\mathrm{ng} / \mathrm{ml})$ & $3.2 \pm 2.8$ & $2.5 \pm 0.7$ & 0.06 \\
\hline Free $\mathrm{T}_{4}(\mathrm{ng} / \mathrm{ml})$ & $1.2 \pm 0.4$ & $1.3 \pm 1.0$ & 0.3 \\
\hline TSH $(\mu \mathrm{IU} / \mathrm{ml})$ & $3.1 \pm 1.9$ & $2.0 \pm 0.8$ & $0.001 *$ \\
\hline TPOAb titre (IU/ml) & $105.0 \pm 150.6$ & $18.5 \pm 9.6$ & $0.001 *$ \\
\hline Gestation at delivery & $38.6 \pm 6.7$ & $38.9 \pm 4.2$ & 0.7 \\
\hline \multicolumn{4}{|l|}{ Mode of delivery } \\
\hline Normal vaginal delivery & $24(77 \%)$ & $51(74 \%)$ & 0.7 \\
\hline Operative vaginal delivery & $1(3 \%)$ & $3(4 \%)$ & \\
\hline Lower segment caesarean section (LSCS) & $4(13 \%)$ & $13(19 \%)$ & \\
\hline Missed abortion & $2(7 \%)$ & $2(3 \%)$ & \\
\hline \multicolumn{4}{|l|}{ Complications } \\
\hline Abortion & $2(7 \%)$ & $2(3 \%)$ & 0.4 \\
\hline Preterm labour (PTL) & $1(3 \%)$ & $11(16 \%)$ & 0.07 \\
\hline Intrauterine growth retardation & $2(7 \%)$ & $4(6 \%)$ & 0.8 \\
\hline Gestational hypertension & $2(7 \%)$ & $4(6 \%)$ & 0.8 \\
\hline Intrahepatic cholestasis of pregnancy (ICP) & $1(3 \%)$ & $4(13 \%)$ & $0.031 *$ \\
\hline Postdatism & $3(10 \%)$ & $3(4 \%)$ & 0.2 \\
\hline Preterm premature rupture of membranes & 0 & $1(1 \%)$ & 0.5 \\
\hline
\end{tabular}

Women with hypothyroidism have decreased fertility (9), even if they conceive, the risk of miscarriage is increased (19). The risk of gestational hypertension, preeclampsia and eclampsia, abruption placentae, post partum haemorrhage, premature delivery and IUGR is increased $(20,21)$. These risks are increased in the whole spectrum of hypothyroidism, including isolated TPO positivity, subclinical hypothyroidism and overt hypothyroidism. In a study by Negro et al. (22), there was a positive association between thyroid autoimmunity with preterm delivery and neonatal respiratory distress syndrome in euthyroid women. However, in our study, neither the TPOAb status (positivity or negativity) nor the presence of subclinical hypothyroidism or euthyroidism affected pregnancy outcome. The occurance of intrahepatic cholestasis of pregnancy was higher in the TPO-positive group than in the TPO-negative group $(P=0.03)$. There was no difference in prevalence of miscarriage between hypothyroid and euthyroid individuals in $\mathrm{TPOAb}^{+}$ women. The prevalence of miscarriage was independent of thyroid status. Similar results were also found with $\mathrm{TPOAb}^{-}$women, when adjusted for age, weight, TFT, TPOAb titre, period of gestation and haemoglobin level.
The miscarriage rate in this study was $4 \%$, which is comparable to a healthy control population. The issue of TPO positivity and the risk of miscarriage in future pregnancies was reported by Pratt et al. (10).

Although multiple studies had demonstrated a risk of miscarriage in patients with AITD, the cause has yet to be established $(6,9,21)$. TPOAb ${ }^{+}$is one of the markers of recurrent miscarriage. However, more evidence is needed before dismissing antibody positivity as a cause of adverse pregnancy outcome (22). The association of thyroid autoimmunity and miscarriage could be due to heightened autoimmune imbalance that in turn leads to a greater rejection rate of the foetal graft, and $\mathrm{TPOAb}^{+}$ women would tend to become pregnant at an older age (3-4 years older, on average), and older women are more prone to pregnancy loss (23). None of this was found in our study.

Recently, Twig et al. (11) described the pathogenesis that underlies infertility and increased pregnancy loss among women with AITD. Thyroid autoantibodies exert their effect in both a TSH-dependent and TSH-independent manner. The latter involves quantitative and qualitative changes in the profile of endometrial T cells, http://www.endocrineconnections.org DOI: 10.1530/EC-13-0012
(C) 2013 The authors Published by Bioscientifica Ltd
This work is licensed under a Creative Commons Attribution 3.0 Unported License. 
which results in the reduced secretion of IL4 and IL10 together with the hypersecretion of interferon- $\gamma$. Polyclonal B-cell activation is two to three times more frequent in thyroid autoimmunity. The hyperactivity and increased migration of cytotoxic natural killer cells which alter the immune and hormonal response of the uterus is up to $40 \%$ more common in women with thyroid autoimmunity. Vitamin D deficiency is also linked to infertility and pregnancy loss, suggesting a potential interplay with thyroid autoimmunity in the context of infertility (11).

On multiple liner regression, the percentage of live births was found to correlate with the level of $\mathrm{T}_{4}$ $(R=0.177, P=0.012)$ and anti-TPO $(R=0.18, P=0.015)$. As expected, the mean TSH in the $\mathrm{TPOAb}^{+}$group was higher $(3.1 \pm 1.9)$ compared with that of the $\mathrm{TPOAb}^{-}$ group $(2.0 \pm 1.0)$. The early evaluation of human thyrocyte TSH receptor stimulating immunoglobulin bioassays with the sera of Graves' disease, Hashimoto's, nonthyroidal auto immune disease and controls, confirms that the cell-based assay of functional immunoglobulin is of clinical importance. It could establish a relationship between the antibodies in question and the disease process $(23,24,25)$.

The strength of our study lies in the use of two agematched control groups, one of non-pregnant women with recurrent miscarriage and another of healthy pregnant women without any history of miscarriage. A single-assay method for TPOAb has been used in the entire study population. The drawbacks of our study were: the small sample size; the fact it is a single-centre study; the lack of a control group that was not treated with $\mathrm{L}-\mathrm{T}_{4}$; and the unavailability of other antibodies such as antithyroglobulin antibody and anti-TSH receptor antibody.

In conclusion, the prevalence of thyroid autoimmunity was higher in pregnant women with a history of recurrent abortion compared with a healthy pregnant control population. Following $\mathrm{L}^{-\mathrm{T}_{4}}$ treatment, there was no difference in the prevalence of miscarriage between hypothyroid and euthyroid individuals in $\mathrm{TPOAb}^{+}$ women. All euthyroid women with thyroid autoimmunity should be treated with $\mathrm{L}_{-} \mathrm{T}_{4}$ to achieve a favourable maternal and perinatal outcome. A large prospective trial of $\mathrm{L}_{\mathrm{L}} \mathrm{T}_{4}$ therapy in TPO-positive euthyroid women is warranted.

\section{Declaration of interest}

The authors declare that there is no conflict of interest that could be perceived as prejudicing the impartiality of the research reported.

\section{Funding}

This research did not receive any specific grant from any funding agency in the public, commercial or not-for-profit sector.

\section{References}

1 Practice Committee of the American Society for Reproductive Medicine. Definitions of infertility and recurrent pregnancy loss. Fertility and Sterility 200890 S60.

2 Brigham SA, Conlon C \& Farquharson RG. A longitudinal study of pregnancy outcome following idiopathic recurrent miscarriage. Human Reproduction 199914 2868-2871. (doi:10.1093/humrep/14.11.2868)

3 Tulppala M, Palosuo T, Ramsay T, Miettinen A, Salonen R \& Ylikorkala OA. A prospective study of 63 couples with a history of recurrent spontaneous abortion: contributing factors and outcome of subsequent pregnancies. Human Reproduction 19938 764-770.

4 Carrington B, Sacks G \& Regan L. Recurrent miscarriage: pathophysiology and outcome. Current Opinion in Obstetrics \& Gynecology 200517 591-597. (doi:10.1097/01.gco.0000194112.86051.26)

5 Li TC, Makris M, Tomsu M, Tuckerman E \& Laird S. Recurrent miscarriage: etiology, management and prognosis. Human Reproduction Update 20028 463-481. (doi:10.1093/humupd/8.5.463)

6 Poppe K \& Glinoer D. Thyroid autoimmunity and hypothyroidism before and during pregnancy. Human Reproduction Update 20039 149-161. (doi:10.1093/humupd/dmg012)

7 Klein RZ, Haddow JE \& Faix ZE. Prevalence of thyroid deficiency in pregnancy. Clinical Endocrinology 199135 41-46. (doi:10.1111/j.13652265.1991.tb03494.x)

8 Wakim AN, Polizotto SL, Buffo MJ, Marrero MA \& Burholt DR. Thyroid hormones in human follicular fluid and thyroid hormone receptors in human granulosa cells. Fertility and Sterility 199359 1187-1190.

9 Faussett MB \& Branch DW. Autoimmunity and pregnancy loss. Seminars in Reproductive Medicine 200018 379-392. (doi:10.1055/ s-2000-13728)

10 Pratt DE, Kaberlein G, Dudkiewicz A, Karande V \& Gleicher N. The association of antithyroid antibodies in euthyroid nonpregnant women with recurrent first trimester abortions in the next pregnancy. Fertility and Sterility 199360 1001-1005.

11 Twig G, Shina A, Amital H \& Shoenfeld Y. Pathogenesis of infertility and recurrent pregnancy loss in thyroid autoimmunity. Journal of Autoimmunity 201238 J275-J281. (doi:10.1016/j.jaut.2011.11.014)

12 Negro R, Formoso G, Mangieri T, Pezzarossa A, Dazzi D \& Hassan H. Levothyroxine treatment in euthyroid pregnant women with autoimmune thyroid disease: effects on obstetrical complications. Journal of Clinical Endocrinology and Metabolism 200691 2587-2591. (doi:10.1210/jc.2005-1603)

13 Yan J, Sripada S, Saravelos SH, Chen ZJ, Egner W \& Li TC. Thyroid peroxidase antibody in women with unexplained recurrent miscarriage: prevalence, prognostic value, and response to empirical thyroxine therapy. Fertility and Sterility 201298 378-382. (doi:10.1016/ j.fertnstert.2012.04.025)

14 Abalovich M, Abalovich M, Mitelberg L, Allami C, Gutierrez S, Alcaraz G, Otero P \& Levalle O. Subclinical hypothyroidism and thyroid autoimmunity in women with infertility. Gynecological Endocrinology 200723 279-283. (doi:10.1080/09513590701259542)

15 Glinoer D, Riahi M, Grün JP \& Kinthaert J. Risk of subclinical hypothyroidism in pregnant women with asymptomatic autoimmune thyroid disorders. Journal of Clinical Endocrinology and Metabolism 1994 79 197-204. (doi:10.1210/jc.79.1.197)

16 Prummel MF \& Wiersinga WM. Thyroid autoimmunity and miscarriage. European Journal of Endocrinology 2004150 751-755. (doi:10.1530/eje.0.1500751)

17 Stagnaro-Green A, Roman SH, Cobin RH, el-Harazy E, Alvarez-Marfany M \& Davies TF. Detection of at-risk pregnancy by

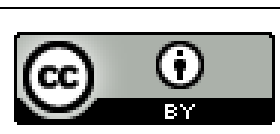


means of highly sensitive assays for thyroid antibodies. Journal of the American Medical Association 1990264 1422-1425. (doi:10.1001/jama. 1990.03450110068029)

18 Bagis T, Gokcel A \& Saygili ES. Autoimmune thyroid disease in pregnancy and the postpartum period: relationship to spontaneous abortion. Thyroid 200111 1049-1053. (doi:10.1089/ 105072501753271743)

19 Wasserstrum N \& Anania CA. Perinatal consequences of maternal hypothyroidism in early pregnancy and inadequate replacement. Clinical Endocrinology 199542 353-358. (doi:10.1111/j.1365-2265. 1995.tb02642.x)

20 Glinoer D, Soto MF, Bourdoux P, Lejeune B, Delange F, Lemone M, Kinthaert J, Robijn C, Grun JP \& de Nayer P. Pregnancy in patients with mild thyroid abnormalities: maternal and neonatal repercussions. Journal of Clinical Endocrinology and Metabolism 199173 421-427. (doi:10.1210/jcem-73-2-421)

21 Ijjima T, Tada H, Hidaka Y, Mitsuda N, Murata Y \& Amino N. Effects of autoantibodies on the course of pregnancy and fetal growth.
Obstetrics and Gynecology 199790 364-369. (doi:10.1016/S0029-7844 (97)00283-4)

22 Negro R, Schwartz A, Gismondi R, Tinelli A, Mangieri T \& Stagnaro Green A. Thyroid antibody positivity in the first trimester of pregnancy is associated with negative pregnancy outcomes. Journal of Clinical Endocrinology and Metabolism 201196 E920-E924. (doi:10.1210/ jc.2011-0026)

23 Tozzoli R, Bagnasco M, Giavarina D \& Bizzaro N. TSH receptor autoantibody immunoassay in patients with Graves' disease: improvement of diagnostic accuracy over different generations of methods. Systematic review and meta-analysis. Autoimmunity Reviews 201212 107-113. (doi:10.1016/j.autrev.2012.07.003)

24 Glinoer D. Miscarriage in women with positive anti-TPO antibodies: is thyroxine the answer? Journal of Clinical Endocrinology and Metabolism 200691 2500-2502. (doi:10.1210/jc.2006-0834)

25 Lytton SD \& Kahaly GJ. Bioassays for TSH-receptor autoantibodies: an update. Autoimmunity Reviews 201010 116-122. (doi:10.1016/j.autrev. 2010.08.018)

Received in final form 1 March 2013

Accepted 2 April 2013 http://www.endocrineconnections.org DOI: 10.1530/EC-13-0012 (c) 2013 The authors Published by Bioscientifica Ltd

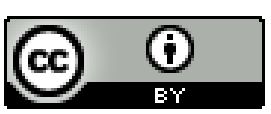

This work is licensed under a Creative Commons Attribution 3.0 Unported License. 